\title{
DE LA POTENCIA INTELECTIVA DEL ALMA Y SU RELACIÓN CON EL CUERPO EN DE ANIMA DE ARISTÓTELES
}

Luis Fernando Mendoza*

RESUMEN: Cuestión central dentro de la epistemología de Aristóteles es saber cuál es la esencia del acto de inteligir y cómo se relaciona con el cuerpo. Primero, se explica la diferencia entre cuerpo viviente y cuerpo no-viviente. Después, la estratificación de las formas de vida que arraigan en un cuerpo viviente, con énfasis en la situación del intelecto. Posteriormente, se referirá la actividad propia de inteligir; y, para terminar, algunas especificaciones acerca de la diferencia entre intelecto activo y pasivo, y una recapitulación sobre cómo se relaciona el intelecto con el cuerpo en el que se halla.

sose

ABSTRACT: SUMMARY: In this article, we explore a main topic in Aristotles' epistemology, namely, what is the act of intellection and its relation to the body. First, we will explore the difference between a living body and a non-living body. Then, we will delve into the stratification of lives in a living body, particularly regarding intellect. Later, we will make reference to the actual act of intellection. Finally, we will specify some differences between active and passive intellect and sum up with the relationship between intellect and the body it inhabits.

PALABRAS CLAVE: Cuerpo, alma, sensibilidad, fantasía, intelecto-pasivo, intelecto-activo, intelección. KEY WORDS: Body, Soul, sensibility, fantasy, passive intellect, active intellect, intellection.

RECEPCIÓN: 26 de abril de 2012.

APROBACIÓN: 6 de septiembre de 2012.

* Departamento Académico de Estudios Generales, ITAM. 
CITAM Derechos Reservados.

La reproducción total o parcial de este artículo se podrá hacer si el ITAM otorga la autorización previamente por escrito. 


\section{DE LA POTENCIA INTELECTIVA DEL ALMA Y SU RELACIÓN CON EL CUERPO EN DE ANIMA DE ARISTÓTELES}

\section{Introducción}

\section{La pregunta acerca de qué sea el} intelecto del alma y cómo opera éste se halla inscrita en la investigación que Aristóteles ha realizado sobre el alma, la cual es de suma importancia para el Filósofo, porque como señala al inicio de su tratado De anima, llegar a saber qué sea el alma contribuye en buena medida a la consecución del saber, y de modo muy señalado al saber acerca de la naturaleza, pues el alma es el principio de los animales, ${ }^{1}$ los cuales a su vez forman parte de la totalidad de la naturaleza. ${ }^{2}$ En el caso específi-

${ }^{1}$ Arist., de An., 402b 7. Sigo la traducción de Tomás Calvo Martínez, Acerca del alma, 1978, Madrid, Gredos.

${ }^{2}$ Expliquemos esto con mayor detenimiento: el interés que despierta en Aristóteles el fenó-

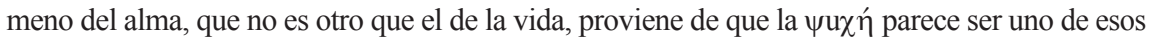
principios naturales, en virtud de los cuales se despliega y se preserva el orden perpetuo del universo. Así, no es exagerado afirmar que, dado que la naturaleza no hace nada en vano y aspi-

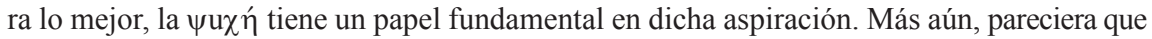
todos los cambios del universo son impulsados de alguna forma desde ese principio que es la vida. Aunado a esto, no se debe olvidar que, para el Estagirita, la actualidad del primer motor inmóvil,

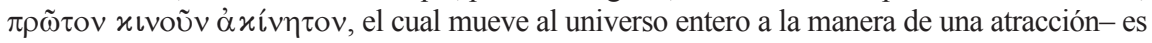

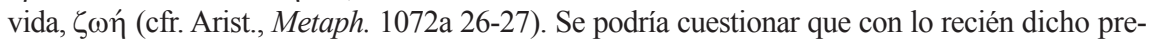
tendemos hacer una identificación entre $\psi$ uұ de dicha identificación. Antes bien, hemos de destacar que, de acuerdo al contexto en el que

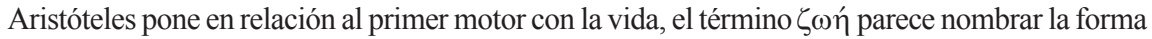
de vida que le es propia al primer motor-vida eterna y nobilísima-y que a fuer de tal, se trata de una vitalidad que no está mezclada con la materia, entendida como principio, esto es, con la posibilidad de ser y no ser. De este modo, la $\psi u \chi \chi ́$ sería ese modo de vida que corresponde 
co de la parte del alma que se denomina potencia intelectiva, se pregunta por aquello que es el principio por el cual es posible a un cierto tipo de animal, al hombre, conocer y pensar todas las cosas a partir de y con vistas a sus principios y causas. Para poder aclarar de un modo suficiente cómo es que se da el conocimiento en general, se requeriría una investigación amplia de todos los tratados de Aristóteles, pues vistas las cosas así, habría que desentrañar la estructura ontológica de lo que es conocido, es decir, de lo ente en general. Pero este propósito excede los límites de nuestra intención. La cuestión que buscamos aclarar y su relevancia se inscriben en el marco epistémico, es decir, tratamos sólo de las condiciones del conocimiento que se dan en nosotros, aunque de un modo tangencial se hagan algunas indicaciones acerca de cómo son las cosas. En este sentido, la pregunta se formula así: ¿en qué consiste el acto de inteligir, cuáles son sus condiciones y cuál es la relación que guarda el intelecto en su actividad con el cuerpo, en el célebre tratado De anima de Aristóteles?

\section{El cuerpo y sus modos}

Aristóteles nos ha dicho que el alma es principio de los animales, y considerando que el intelecto del que nos habla en De anima está inscrito en el ámbito de los entes naturales, debemos mostrar en primer lugar los rasgos generales de lo que es un animal en tanto que ente natural. En la totalidad de la naturaleza podemos distinguir dos tipos de cuerpos $(\sigma \omega ́ \mu \alpha \tau \alpha)$ : los cuerpos vivos y los carentes de vida. Los cuerpos vivientes son aquellos que se constituyen de tal manera que son aptos para que

a los entes compuestos, a las cosas que se mueven en el ámbito de la generación y la corrupción. En efecto, la $\psi u \chi \chi ́$ es principio de vida de un cierto tipo de cuerpos, y en consecuencia, es algo finito, en cuanto al número, pero no en cuanto a la especie - es decir, la especie de los seres vivos

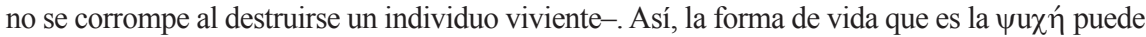
ser denominada propiamente como vida perpetua, pues como señala Aristóteles: "Y es que para todos los vivientes que son perfectos [...] la más natural de las obras consiste en hacer otro viviente semejante a sí mismos [...] con el fin de participar de lo eterno y divino en la medida en que les es posible: todos los seres, desde luego, aspiran a ello y con tal fin llevan a cabo cuantas acciones realizan naturalmente." (Arist., de An., 415a 26-415b 2). 
brote en ellos la vida, mientras que en los no vivientes no brota la aptitud para la vida, no se concreta en ellos la potencia de vivir. La efectiva diferencia entre uno y otro tipo de cuerpo radica en que los que tienen vida poseen por sí la potencia de autoalimentarse, crecer y envejecer, en virtud del desarrollo de órganos aptos para tales actividades. El desarrollo de órganos se da con vistas a que la vida pueda hacerse presente en el cuerpo organizado. Así, el Estagirita acaba por afirmar del cuerpo viviente que: "si cabe enunciar algo general acerca de toda clase de alma, habría que decir que es la entelequia primera de un cuerpo natural organizado". ${ }^{3}$ Aquello que dota de vida a estos cuerpos, que actualiza en ellos su poder de vida es, precisamente, el alma, y por ello todo cuerpo natural que tiene vida es una entidad compuesta, es decir, se trata de aquel tipo de cuerpo que entraña la característica distintiva de la forma específica de la vida. El cuerpo, en los entes naturales que poseen vida, funge como materia y sujeto, como poder ser, mientras que el alma constituye su forma de concreción definitoria-como puede verse en la definición de alma, donde se caracteriza como "entelequia primera de un cuerpo natural que en potencia tiene vida". En esta composición se deja ver ya que el alma no es cuerpo, sino la forma que da concreción y definición a una cierta potencia de éste, si bien no puede ella darse sin un cuerpo, y por tanto, siempre forma parte de una entidad compuesta. Así las cosas, sería casi inmediato pensar que toda la actividad del alma tiene alguna vinculación con el cuerpo. Justo en este punto formulamos la pregunta, a saber, si hay una afección, potencia o actividad del alma que pueda darse con plena independencia del cuerpo. Tradicionalmente se ha pensado que el inteligir puede ser esa actividad que no depende en modo alguno del cuerpo viviente, y por ello hemos de poner en evidencia, de la mano de Aristóteles, si en efecto sucede así. En caso de que no sea así, habrá que poner a la vista cómo se da la actividad de inteligir en tanto que ligada al cuerpo y en qué consiste dicho ligamen. Ahora bien, al parecer, el alma no puede hacer nada ni padecer nada sin el cuerpo, pues en

${ }^{3}$ Arist., de An., 412b 4-5.

${ }^{4}$ Ibid., 412a 28-30 (cursivas mías). 
éste ella se da, y así, es preciso que ella utilice al cuerpo para poder llevar a cabo sus actividades. Así parece afirmarlo el propio Aristóteles: "el inteligir parece algo particularmente exclusivo de ella [sc. del alma]; pero esto ni siquiera podrá tener lugar sin el cuerpo si es que se trata de un cierto tipo imaginación o de algo que no se da sin imaginación". 5

\section{Posibilidad y estructura de la vida en el cuerpo}

Como ya hemos dicho, el alma es el principio de vida de los cuerpos naturales. Sin embargo, no todo cuerpo natural está dispuesto naturalmente para poseer alma, sino que ésta sólo se da en la materia o cuerpo adecuado, y sólo esta materia o cuerpo adecuado, que funge como sujeto, es aquello que tiene la potencia y disposición para la vida. Una vez que en la materia o el cuerpo brota el alma, ésta funge como forma definitoria de aquél, y puede decirse entonces que el alma es entelequia primera de un cuerpo natural que en potencia tiene vida. Aristóteles va más allá. Si bien el alma es principio de vida en el cuerpo organizado, esta potencia se corresponde, en todo caso, con el cuerpo específico en el que el alma se encuentra, es decir, la potencia de la vida se halla determinada por la singularidad de la entidad compuesta y organizada, como lo es la planta, el animal o el hombre. Así, no son las mismas potencia y actividad vitales que se dan en una planta que las que se dan un animal, porque en el caso de la primera su cuerpo sólo puede albergar y desplegar la potencia y actividad nutritiva ( $९ \rho \varepsilon \pi \tau \iota x o ́ v),{ }^{6}$ mientras

${ }^{5}$ Ibid, 403a 8.

${ }^{6} \mathrm{La}$ afirmación de Aristóteles acerca de que en las plantas sólo se da la potencia vegetativa está fundada en el camino que le era accesible, en su tiempo, desde los asuntos mismos. En efecto, los avances positivos de la ciencia pueden llegar a poner en evidencia que en la plantas hay no sólo la potencia vegetativa, sino también la sensible, e incluso otras más perfectas. Pero a nuestro parecer, la genuina contribución aristotélica no radica tanto en su clasificación de los seres vivos; antes bien, se nos presenta en su descripción de los actos vitales propios de los cuerpos vivientes. A lo largo del paso del tiempo nos sigue siendo evidente que los cuerpos que viven se sostienen en su ser a partir de su efectiva capacidad para alimentarse, crecer, reproducirse y envejecer. De igual modo, si bien podemos decir que hay imprecisión en las descripciones acerca de la actividad sensible realizada por Aristóteles, también debemos 
que en el otro, en virtud de sus órganos, se da tanto la potencia y la acti-

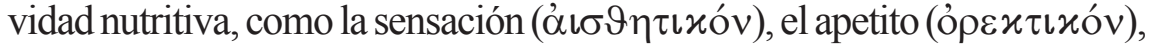

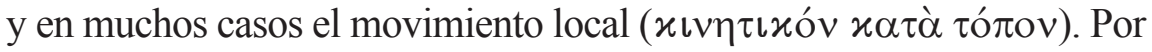
ello, se va haciendo evidente que el alma despliega sus potencias siempre en virtud del cuerpo en el que se encuentra, a tal punto que si un órgano del cuerpo llega a atrofiarse, la potencia del alma que se corresponde con dicho órgano ya no posee el sustrato material, la potencia o posibilidad de ser apropiada para desplegarse.

Ahora bien, cuando se destruye una facultad, no es necesario que se corrompa todo el cuerpo viviente; la destrucción del viviente sólo se da al corromperse la capacidad corporal para la vegetación, pero no si se destruyen las aptitudes, los órganos sensitivos, o bien si se destruyen los del movimiento. En virtud de lo anterior, se pone a la vista que las potencias del alma poseen una estratificación que se da a partir de las potencias más básicas de la vida hacia sus potencias más excelentes -esto es, aquellas cuyo ámbito de relación con la realidad es más universal-. En el estrato inferior está la vegetación, pues lo vivo en general se define por autoalimentarse y reproducirse. En el siguiente estrato se encuentra la sensación que, si bien sólo es posible sobre la base de la nutrición, posee también un ámbito de despliegue más amplio, como puede verse en que los vivientes dotados de sensación, los animales, son capaces de discernir cualidades, formas sensibles en los alimentos, actividad que, según Aristóteles, las plantas no pueden llevar a cabo. Y a esto se añade lo siguiente: al haber sensación, se da también el placer y el dolor, y con ello, el poder apetecer; ${ }^{7}$ en efecto, al percibir el aspecto de lo deseable o doloroso, surge el impulso para ir tras ello o rehuirle. Así, en algunos animales, a la vez que se da el apetito, se da el poder del movimiento por el que se va de un lugar a otro en busca de lo placentero y se rehúye lo doloroso. Sin embargo, dada la estructura psíquica, si se destruyen la sensación y la nutrición en el animal, también se imposibilitan el apetito y el movimiento, y finalmente, la vida toda. ${ }^{8}$

asentir en que la caracterización de la actividad sensible como aprehensión formal de la realidad sigue siendo de peso al momento de discutir acerca de qué y cómo es el sentir.

${ }^{7}$ Cfr. ibid., 413b 20-5.

${ }^{8}$ Se debe precisar por qué la sensación no es una facultad idéntica al apetito. La distinción radica en tener presente que una facultad se constituye por tres cosas: la aptitud de pa- 
Pero, ¿qué sucede respecto del intelecto en esta estructuración del alma? El intelecto, en tanto que potencia del alma, sólo se da en aque1los animales que poseen todas las demás potencias anímicas, algunas de las cuales son inherentes a los órganos del cuerpo y se actualizan por medio de ellos. ${ }^{9}$ Sin embargo, dice Aristóteles en su tratado acerca de la reproducción de los animales, en el acto propio del intelecto, que el cuerpo no participa para nada en su actividad; el intelecto no precisa de un órgano corporal para el despliegue de su potencia. ${ }^{10}$ Así, las potencias nutritiva, sensitiva, apetitiva y motriz precisan de órganos corporales como la boca o las raíces, la carne, los ojos o los pies, pero el intelecto no tiene un órgano por medio del cual se ponga en acto o por el que resulte afectado, y por ende, es impasible y se genera en el alma de modo distinto al de las potencias restantes. Nos dice el Estagirita de un modo enigmático que el intelecto del alma llega desde fuera y es incorpóreo. No obstante, no debemos olvidar que no es del todo impasible respecto del cuerpo, pues en caso de que se destruyan las potencias inferiores del alma -lo cual sucede cuando se destruyen los órganos mediante los que se actualizan las potencias del alma-, también se socava la posibilidad de que se dé la potencia del intelecto. Vistas las cosas de este modo, el intelecto es inseparable del cuerpo

decer, el acto de dicha aptitud y el objeto en concurso con el cual se da el acto. Si sensibilidad y apetito fueran lo mismo en esencia, entonces deberían coincidir en esos tres aspectos. Sin embargo, no es así. La sensibilidad no está referida propiamente a las mismas cosas que el apetito y, por ello, sus actividades respectivas no pueden ser idénticas, lo cual hace que su poder esté diferenciado, aunque sea al modo de otra disposición del alma misma. El objeto propio de la sensibilidad son las formas sensibles, mientras que el del apetito es lo placentero y lo doloroso. El acto del sentir es apropiarse de la forma sensible en presencia de la cosa, mientras que la actividad del apetecer consiste en extenderse y retraerse, a partir de lo apropiado sensiblemente, de aquello que parece deseable y doloroso. Así, la aptitud de sentir y de apetecer se muestran diferentes.

${ }^{9}$ En el caso de la fantasía, su acto no implica un movimiento corporal, pero dicho acto sólo se da sobre la base de la sensibilidad, y en este sentido guarda cierta relación con el cuerpo, es decir, sólo hay imaginación si un órgano corporal ha sido afectado por el objeto sensible. Por razones de extensión no podemos precisar cómo, en la formación de imágenes, no se necesita la presencia de un objeto externo, si bien la imagen es algo que se genera a partir de la percepción en acto de una forma sensible.

${ }^{10}$ Cfr. Arist., GA, 736b 28. Sigo la traducción de Ester Sánchez, Reproducción de los animales, 2008, Madrid, Gredos. 
en tanto que potencia del alma -pues ésta se da siempre en un cuerpo-, pero es separable en su actividad al no precisar de órgano corporal alguno.

\section{El acto de la intelección y sus distinciones respecto de la sensibilidad}

Al parecer de Aristóteles, sus predecesores afirmaron de un modo ambiguo que el sentir y el inteligir son la misma actividad, lo cual no parece ajustarse a la naturaleza de las cosas. Por ello, su intención radica en mostrar cuál es la característica que distingue al inteligir del sentir. Sobre esta base, Aristóteles afirma que la semejanza entre estas acciones se da en virtud de que ambas implican un padecer influjo mediante sus objetos respectivos, es decir, a partir de los objetos sensibles e inteligibles. De igual modo, se deja ver que una primera diferencia entre ambas facultades consiste en estar referidas o dispuestas para distintos momentos de los objetos que se presentan al alma, esto es, que aquello que ejerce influjo en ellas no son objetos separados ontológicamente, sino que se trata de una misma cosa que puede presentar tanto un aspecto sensible como uno inteligible. Así, la dificultad de la diferencia entre el sentir y el inteligir radica es discernir en qué consiste cada uno de estos momentos. En este sentido, la facultad de inteligir sólo padece influjo bajo la acción de lo inteligible, "o bien en algún otro proceso similar". ${ }^{11}$ Y este influjo que puede padecer la potencia intelectiva no se percibe mediante órgano alguno, como sí se da en la potencia sensible.

En aparente contradicción con lo que acabamos de señalar, Aristóteles afirma que siendo impasible el intelecto ha de poder recibir la forma, esto es, ha de poder ser tal y como la forma; pero este poder ser como la forma implica que, en tanto potencia, el intelecto no es ya una forma inteligible, sino que ha de poder llegar a ser como ella una vez que esté en acto. Decimos que se trata de una contradicción aparente, pues el padecer influjo propio del intelecto no debe entenderse como una des-

${ }^{11}$ Arist., de An., 429b 15. 
trucción por la acción del contario, sino como "la conservación de lo que está en potencia por la acción de lo que está en entelequia, siendo lo uno y lo otro semejantes entre sí -en la medida en que esta semejanza corresponde a la relación existente entre potencia y entelequia". ${ }^{12}$ Aquí es visible otra semejanza entre la potencia sensible-la cual no debemos olvidar que se liga en todo punto con el cuerpo- y la inteligible, en la medida en que ambas pueden ser definidas como potencias capaces de recibir formas, si bien la diferencia entre ambas sigue siendo el tipo de forma que recibe y cómo la recibe.

Ahora bien, en la medida en que la facultad intelectiva es capaz de inteligir todas las cosas - capaz de recibir todas las formas-, ella es sin mezcla con el cuerpo, pues si estuviera mezclada, tendría alguna de las propiedades del cuerpo, sea el tamaño, la cantidad o la cualidad; si tuviera alguna propiedad corporal, la facultad intelectiva recibiría las cualidades sensibles, contrario a su naturaleza, y por tanto, estaría impedida para llevar a cabo el acto que le es propio, a saber, recibir las formas inteligibles; en última instancia, no sería en nada distinta de la facultad sensitiva. ${ }^{13}$ No es que el intelecto no se refiera a las cualidades de las cosas, sino que él las intelige en su esencia, en su razón de ser, lo cual es esencialmente diferente de captar las cualidades sensibles de las cosas. Así, hay una diferencia en el modo en el que se ejecutan los actos de la sensación y de la intelección. Para poder entender esta diferencia, es preciso que recordemos que la facultad sensitiva sí tiene una proporción idónea de todas las cualidades sensibles -la cual se halla ínsita en la potencia vital de los órganos sensoriales del cuerpo-, en virtud de la cual es capaz de sentir con justeza y de discernir las tonalidades, los matices de los objetos sensibles. Pero la facultad intelectiva no tiene naturaleza alguna distinta de su potencia para recibir las

${ }^{12}$ Ibid., $417 \mathrm{~b} 1$.

${ }^{13}$ Con lo recién dicho sólo hemos indicado lo que el intelecto no es. En un sentido afirmativo, debemos decir que el intelecto se halla dispuesto en su actividad en un ámbito distinto al de la sensibilidad, más radical. Esta radicalidad consiste en que la actividad del intelecto abre y dispone a las cosas en la esfera propia de la intelección, en la que las cosas son vistas desde su formalidad inteligible, la cual está regida por las causas y los principios. Cómo el intelecto abre este ámbito, esta esfera, lo explicaremos más adelante. 
formas inteligibles, no posee proporción ni tiene un órgano mediante el cual lleve a cabo su actividad; tampoco le es inherente cualidad corpórea alguna y, por ello, es sin mezcla. Así, subraya el Estagirita: "el denominado intelecto del alma -me refiero al intelecto con el que el alma razona y enjuicia- [razonar y enjuiciar son actos propios del intelecto, y no de la sensibilidad] no es en acto ninguno de los entes antes de inteligir". ${ }^{14}$ Este no ser en acto ningún ente antes de inteligir significa que el intelecto sólo es la potencia -sin naturaleza determinada- de recibir las formas, potencia que se actualiza y que está en su propio fin, en su acto, cuando recibe el influjo de las formas inteligibles. ${ }^{15}$

El aspecto común entre ambas facultades consiste en que su actividad radica en un padecer, en un estar dispuestas para recibir el influjo de las formas sin la materia. Sin embargo, esta comunidad o semejanza entre sensibilidad e intelecto tiene también su rasgo distintivo. El padecer de la sensibilidad, en tanto que implica una armonía que se haya ínsita en el órgano potencializado por "su" alma, se da precisamente como un sentir con medida y justeza, y si el padecer es excesivo, si el influjo del objeto es muy fuerte y rompe con la armonía, entonces no se da el acto de sentir, ni tampoco se recibe la forma del objeto sensible. Por el contrario, el intelecto al padecer el influjo de algo fuertemente inteligible, ejecuta el acto de intelección con una mayor agudeza y precisión. Así, podemos decir que el padecer de la sensibilidad se da en virtud de la proporción y la armonía que hay entre el objeto y la facultad, y que el padecer del intelecto acontece en

${ }^{14}$ Arist., de An., 429a 22.

${ }^{15} \mathrm{Se}$ debe tener presente que en el acto de intelección hay una sola actualización con carácter bifronte: por una parte, la del intelecto del alma y, por otra, la de la cosa inteligida. Lo que la cosa es, en tanto inteligida, no es algo que el intelecto crea a partir de su actividad, sino algo que aquél ha tomado de la cosa, y esto que ha tomado es algo que pertenece a la cosa por naturaleza, si bien sólo se halla potencialmente en la cosa antes del acto de la intelección. En éste, la cosa da de sí su forma inteligible y el intelecto toma esa forma; por ello se trata de una sola actualización que repercute en entidades distintas. Quizás por esta unidad de la actualización de la intelección Anaxágoras decía que el intelecto, que es sin mezcla, mantiene a todas las cosas reunidas, pues si fuera algo mezclado, sería algo reunido y no lo que reúne. 
razón de la fuerza propia del objeto inteligible con la que éste ejerce influjo en la facultad intelectiva, la cual es sin mezcla y separable.

\section{El intelecto y el cuerpo}

Sin embargo, a pesar de que el intelecto es sin mezcla y separable, sigue estando referido a las mismas cosas que la sensibilidad, como sigue inmerso en el ámbito de la naturaleza, si bien la operación por las que captan sus objetos respectivos es distinta. Porque si bien, hasta este punto Aristóteles ha mostrado ya algunas de las diferencias entre la sensibilidad y el intelecto, éstas podrían hacer pensar que éste último no se refiere a la misma realidad que aquélla, en virtud de la separabilidad de ambas facultades. Así, Aristóteles acaba por hacer una distinción ignorada por sus predecesores, que abre una vía por la cual se aclara la semejanza y la diferencia entre sentir e inteligir: en un sentido, cabe decir que aquello con lo que el alma discierne la cualidad y la esencia de la cualidad son facultades distintas, y por otra-sin que ello vaya en detrimento de la primera-, se trata de una sola facultad dispuesta de distinta manera. Para Aristóteles, la sensibilidad y el intelecto son, en un sentido, facultades distintas y en otro la misma, pero dispuesta de modo diferente. Que se trata de facultades distintas se debe a que en el orden de la operación, del acto, el intelecto se llega a hacer idéntico a la forma que ejerce influjo en él; se hace semejante a la forma inteligible, y ésta es esencialmente distinta de la forma sensible que se capta en el acto de la facultad sensitiva. Lo que capta en acto una y otra facultad es distinto, y por ende, se trata de facultades, que en tanto operan, son distintas. Pero en el orden de la potencia ambas facultades son la misma, dispuesta de modo distinto, en tanto que ellas, la sensibilidad y el intelecto, son el lugar de las formas, sean sensibles, sean inteligibles.

En razón de esto, el intelecto y la facultad sensitiva son dos aspectos que pertenecen a una misma alma, o bien, son dos modos en los que puede disponerse una sola alma respecto de sus objetos, pues reciben influjo de la misma cosa, a la vez que el aspecto que ejerce influjo en 
ellas no es el mismo en todo punto. El Estagirita concluye que el intelecto es separable de la sensibilidad del mismo modo en que los objetos son separables de la materia. La separabilidad del intelecto en el alma tiene un carácter formal y operacional, y no un carácter real, porque así como en las cosas materiales las cualidades sensibles se dan en la materia, y son estas cualidades las que, en tanto que formas sensibles, son separadas de la materia en el acto de sentir, así el intelecto está en una misma alma que, necesariamente, posee sensibilidad; cuando se halla en el acto que le es propio, se separa de la facultad sensitiva para poder tomar la forma inteligible. Por ello, en el capítulo I del primer libro de De anima, Aristóteles afirma que la relación del intelecto del alma con el cuerpo es análoga a la de la línea recta, que es tangente en la esfera de bronce, ${ }^{16}$ pues así como la recta tangente sólo toca en un punto a la esfera y sólo en este punto dicha recta es tangente -sólo en ese punto se despliega su esencia de ser tangente, pues no hay rectas tangentes sin un cuerpo al que toquen al menos en un punto-, así el intelecto del alma se halla al menos en un punto ligado al cuerpo desde el momento en que no puede llegar a inteligir nada sin el concurso de las imágenes que producen las sensaciones, la cuales sólo se dan cuando hay un órgano corporal que siente. Aristóteles explica, en el capítulo octavo del libro III de De anima, cómo el intelecto toma la forma inteligible de las cosas y afirma, por una parte, que el alma dianoética jamás intelige sin el concurso de una imagen $y$, por otra, que el intelecto capta las formas en las imágenes. Al ser las imágenes algo que se genera a partir de lo que toma la sensibilidad, a saber la figura de las cosas, podemos arriesgarnos a decir con Aristóteles que las formas inteligibles se hallan de algún modo ya en las formas sensibles de las cosas, y muy señaladamente en las imágenes que se producen con las sensaciones en acto. En última instancia, las imágenes sirven al intelecto como figuras (esquemas) a partir de las cuales hace y toma las formas inteligibles de las cosas. Por lo demás, es evidente que el intelecto del alma no puede inteligir nada sin el concurso -no material, sino formal-del cuerpo.

${ }^{16}$ Cfr., Arist., de An., 413a 13. 


\section{Acerca del intelecto activo y pasivo}

¿Cómo el intelecto es inteligible para sí, si sólo puede inteligir con el concurso de formas o esquemas que, por una parte, no son idénticos a las formas inteligibles, y que por otra, provienen de actualizaciones de potencias del alma que están ligadas a las afecciones del cuerpo? La pregunta se agrava aún más si tomamos en cuenta lo que en $\mathrm{Me}$ tafísica XII se enuncia: "pero la ciencia, la sensación, la opinión y el pensamiento parecen ser siempre de otra cosa, y sólo secundariamente de sí mismos". ${ }^{17}$ Respecto a esta dificultad, Aristóteles sostiene que el intelecto es inteligible para sí, tal y como sus objetos son inteligibles, es decir, él mismo ya está intelección de sí desde el momento en que capta, toma y se hace idéntico con las formas inteligibles. Por ello, respecto de los seres inmateriales -aquellos entes que en su naturaleza no guardan relación alguna con la materia, como es el caso del primer motor-, cabe decir que lo que intelige y lo inteligido son idénticos; lo que capta el intelecto en su acto de inteligir es el intelecto mismo -pues el intelecto es inmaterial-, razón por la cual en esta clase de entes se trata de intelección de intelección, intelecto que se capta primaria y únicamente a sí mismo. ${ }^{18}$ En los entes corporales, materiales, lo inteligible sólo se halla en ellos potencialmente, pues aquello que puede tenerlos como objeto es algo de naturaleza inmaterial. Por ello, es preciso que antes de poder tomar las formas inteligibles de las formas provenientes de la naturaleza material de las cosas, se dé un acto por el cual esas cosas se hagan adecuadas a la naturaleza del intelecto, es decir, un acto en virtud del cual los entes materiales se hagan susceptibles de ser inteligibles. En el caso del alma humana, dicho acto es es el modo en que el intelecto que se da en las entidades compuestas se intelige a sí mismo. Esto no contradice el hecho de que el intelecto del alma humana sólo se capte a sí mismo secundariamente, pues cuando el intelecto del alma se capta a sí mismo es porque está inteligiendo,

${ }^{17}$ Arist., Metaph. 1074b 35. Sigo la traducción de Valentín García Yebra, Metafísica, 1982, Madrid, Gredos.

${ }^{18}$ Cfr. ibid., $1074 \mathrm{~b} 33$. 
en primera instancia, a una entidad distinta de sí, y no porque primero se capte a sí mismo y luego a las cosas. Dicho de otra forma, el intelecto del alma se capta a sí secundariamente debido a que, cuando intelige, tiene por objeto de intelección a otra cosa y no a sí mismo, lo cual es lo mismo que decir que el intelecto del alma es inteligible para sí sólo en tanto que hace inteligible a las cosas.

Se debe recordar, así, que las relaciones de las cosas en la naturaleza entera implican un principio activo y otro pasivo; en el intelecto debe darse, pues, la misma relación. El intelecto del alma es aquello que puede llegar a ser todas las cosas, aquello que padece el influjo de lo inteligible. Pero en el intelecto del alma también se da un principio activo en virtud del cual aquél hace inteligibles todas las cosas, y por ello, dicho intelecto agente guarda una relación análoga con el principio activo de la naturaleza. Este intelecto activo es una disposición habitual, una ${ }^{\varepsilon} \xi \iota \varsigma$, como la luz, que hace visible a los objetos, a los colores. De igual modo, el intelecto agente hace que las cosas que no son intelecto -las formas mezcladas con la materia- se hagan inteligibles, que estén dispuestas en el ámbito propio de la intelección. De este modo, estando los objetos inteligibles en potencia en las cosas materiales, el intelecto agente actualiza esa potencialidad en esa clase de cosas y las hace inteligibles en el modo de hacerlas semejantes, de ponerlas a disposición de la naturaleza del intelecto. El modo en el que hace inteligibles a las cosas materiales, insistimos, no se da directamente en las cosas, sino a partir de las formas y de los esquemas que ha tomado y formado el alma en virtud de la sensación y la imaginación. El intelecto no efectúa ningún cambio en la realidad efectiva de las cosas, sino que actúa sólo respecto de las formas alojadas en el alma, las cuales son siempre tomadas de las cosas. Sólo en el alma las cosas se hacen semejantes, en un sentido formal, al intelecto. Y sólo cuando se han hecho semejantes a dicha naturaleza pueden ser captadas en su esencia. Esto no quiere decir que el intelecto agente guarde respecto del paciente una anterioridad temporal, sino que se trata de una anterioridad estructural, pues si bien es preciso que primero se dé el acto por el cual las cosas se hacen inteligibles, tal acto tiene su pleno 
cumplimiento cuando, a partir de dicho acto, se toma y se recibe la forma inteligible. Empero, la anterioridad estructural del intelecto agente no significa que el intelecto se capte primariamente a sí mismo o que se tenga primariamente a sí mismo como objeto de intelección, sino que se capta a sí mismo en tanto que hace que cosas que son naturalmente distintas a él se hagan inteligibles. No obstante, a pesar de la unidad estructural de los aspectos del intelecto, su aspecto agente es lo más excelso de su naturaleza porque posibilita al aspecto paciente e impide su corrupción. No se trata de dos intelectos, sino de uno solo cuyos aspectos están estructurados en su modo de operar. Y este único intelecto del alma es separable, impasible, siempre se halla en acto en la medida de sus posibilidades - es decir, en tanto el cuerpo en el que está tiene viday siempre se intelige a sí en el modo de hacer formalmente inteligibles las cosas, en la medida en la que dispone el fondo sobre el cual se llega mostrar el aspecto inteligible de la naturaleza.

\section{Conclusiones}

El llamado intelecto del alma no podría inteligir nada si no estuviese en algún punto ligado al cuerpo. Aun cuando en su actividad no requiere de órgano alguno y se separa formalmente del cuerpo con la finalidad de ver las cosas en y desde el ámbito de la inteligibilidad, aquello que le sirve como materia para su actividad no es algo que el intelecto del alma se dé a sí mismo, sino que le es brindado por las otras potencias del alma que están íntimamente ligadas al cuerpo. Por otra parte, y con vistas a la consecución del conocimiento, es evidente que a medida que el hombre avanza en su saber acerca de la razón de ser de las cosas, de los principios y las causas, está volcado cada vez más a un trabajo interior; en palabras de Aristóteles, "la ciencia [en acto] es de universales y éstos se encuentran en cierto modo en el alma misma". ${ }^{19}$ Este trabajo interior, empero, no debe entenderse como un no mirar más a las cosas como se presentan inmediatamente para la sensibilidad

${ }^{19}$ Arist., de An., 417b 22. 
o la imaginación, sino pensar a partir de lo que ofrecen esas potencias en el ámbito de la intelección. En la búsqueda del saber, en la vida teorética, opera un cambio de modo de mirar, una modificación en la forma como el hombre se relaciona con las cosas, a partir de la cual lo que se busca es precisamente contemplar las cosas desde y con vistas a sus principios y causas. 
CITAM Derechos Reservados.

La reproducción total o parcial de este artículo se podrá hacer si el ITAM otorga la autorización previamente por escrito. 